Original paper

\title{
Towards an updated ESTRO-EFOMP core curriculum for education and training of medical physics experts in radiotherapy - A survey of current education and training practice in Europe
}

\author{
Cristina Garibaldi ${ }^{\mathrm{a}, *}$, Marion Essers ${ }^{\mathrm{b}}{ }^{\text {, Ben Heijmen }}{ }^{\mathrm{c}}$, Jenny Bertholet ${ }^{\mathrm{d}}$, Efi Koutsouveli ${ }^{\mathrm{e}}$, Ad J. \\ J. Maas $^{\mathrm{f}}$, Margaret Moore ${ }^{g}$, Borislava Petrovic ${ }^{\mathrm{h}, \mathrm{i}}$, Irena Koniarova ${ }^{\mathrm{j}}$, Albert Lisbona $^{\mathrm{k}}$, \\ Tomasz Piotrowski $^{1}$, Raphaël Moeckli ${ }^{\mathrm{m}}$, Antonio López Medina ${ }^{\mathrm{n}}$, Erato Stylianou Markidou ${ }^{\circ}$, \\ Catharine H. Clark ${ }^{\mathrm{p}, \mathrm{q}, \mathrm{r}}$, Nuria Jornet ${ }^{\mathrm{s}}$
}

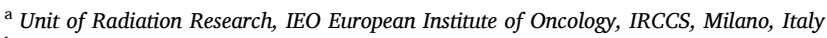

${ }^{\mathrm{b}}$ Department of Medical Physics and Instrumentation, Institute Verbeeten, Tilburg, The Netherlands

${ }^{\mathrm{c}}$ Division of Medical Physics, Department of Radiation Oncology, Erasmus MC Cancer Institute Erasmus University, Rotterdam, The Netherlands

${ }^{\mathrm{d}}$ Division of Medical Radiation Physics, Department of Radiation Oncology, Inselspital, Bern University Hospital, University of Bern, CH 3010 Bern, Switzerland

e Department of Medical Physics, Hygeia Hospital, Athens, Greece

${ }^{\mathrm{f}}$ Formerly Department of Medical, Information and Communication Technology, Jeroen Bosch Ziekenhuis, 's-Hertogenbosch, The Netherlands

${ }^{g}$ Department of Medical Physics \& Clinical Engineering, University Hospital Galway, Newcastle Road, Galway H91, YR71, Ireland

h Department of Physics, Faculty of Sciences, University of Novi Sad, Novi Sad, Serbia

${ }^{i}$ Radiotherapy Department, Oncology Institute Vojvodina, Sremska Kamenica, Serbia

${ }^{\mathrm{j}}$ Section of Medical Exposures, Department of Radiation Protection in Radiotherapy, National Radiation Protection Institute, Prague, Czech Republic

${ }^{\mathrm{k}}$ SFPM, Department of Medical Physics, Institut de Cancérologie de l'Ouest 44805 Saint-Herblain, France

${ }^{1}$ Department of Electroradiology, Poznan University of Medical Sciences and Department of Medical Physics, Greater Poland Cancer Centre, Garbary 15 st, $61-866$ Poznan, Poland

${ }^{\mathrm{m}}$ Institute of Radiation Physics, Lausanne University Hospital and Lausanne University, Lausanne, Switzerland

${ }^{\mathrm{n}}$ Medical Physics Department, Galaria, Hospital do Meixoeiro, Complexo Hospitalario Universitario de Vigo, Vigo, Spain

${ }^{\circ}$ Medical Physics Department, Bank of Cyprus Oncology Centre Nicosia, Cyprus

${ }^{\mathrm{p}}$ Department of Radiotherapy Physics, University College London Hospital, London, UK

${ }^{\mathrm{q}}$ Department of Medical Physics and Bioengineering, University College London, London, UK

${ }^{\mathrm{r}}$ Medical Physics department, National Physical Laboratory, Teddington, UK

${ }^{\mathrm{s}}$ Servei de Radiofisica i Radioprotecció, Hospital de la Santa Creu I Sant Pau, Barcelona, Spain

\section{A R T I C L E I N F O}

\section{Keywords:}

Education

Training

Medical physics expert

Radiotherapy

Core curriculum

\begin{abstract}
A B S T R A C T
Purpose: ESTRO-EFOMP intend to update the core curriculum (CC) for education and training of medical physicists in radiotherapy in line with the European Commission (EC) guidelines on Medical Physics Experts (MPE), the CanMEDS methodology and recent developments in radiotherapy. As input, a survey of the current structure of radiotherapy MPE national training schemes (NTS) in Europe was carried out.

Methods: A 35-question survey was sent to all European medical physics national societies (NS) with a focus on existence of an NTS, its format and duration, required entry-level education, and financial support for trainees.

Results: Twenty-six of 36 NS responded. Twenty had an NTS. Minimum required pre-training education varied from BSc in physics or related sciences $(5 / 2)$ to MSc in medical physics, physics or related sciences $(6 / 5 / 2)$ with 50-210 ECTS in fundamental physics and mathematics. The training period varied from 1 to 5 years (median 3 years with $50 \%$ dedicated to radiotherapy). The ratio of time spent on university lectures versus hospital training was most commonly $25 \% / 75 \%$. In 14 of 20 countries with an NTS, a research project was mandatory. Residents were paid in 17 of 20 countries. The recognition was mostly obtained by examination. Medical physics is recognised as a healthcare profession in 19 of 26 countries.
\end{abstract}

\footnotetext{
* Corresponding author.

E-mail address: cristina.garibaldi@ieo.it (C. Garibaldi).
} 
Conclusions: The NTS entrance level, duration and curriculum showed significant variations. This survey serves to inform the design of the updated CC to define a realistic minimum training level for safe and effective practice aiming at further harmonization in line with EC guidelines.

\section{Introduction}

Radiotherapy (RT) is a highly technical therapeutic approach to treat cancer patients with ionising radiation. A thoroughly trained multidisciplinary team, including radiation oncologists, medical physicists, RT technicians/radiation therapists/radiographers and oncology nurses, has the responsibility to ensure a safe and effective treatment for all patients. As a scientist trained in fundamental physics and specialized in medical physics, the medical physicist has a unique role in this clinical team [1]. Apart from physics, also medical, radiobiological and information technology aspects of radiotherapy are covered in the training of radiotherapy physicists.

The medical physicist in RT has three main responsibilities: 1) leading physics aspects of RT (including choice, commissioning and management of equipment, treatment planning, quality assurance, imaging, patient-specific dosimetry and radiation protection), 2) training of personnel, 3) research and innovation. The medical physicist is also involved in consultations with patients on physics related topics.

The importance of the medical physicist in the RT environment was recognized at an early stage: The American Society for Therapeutic Radiology and Oncology (ASTRO), founded in 1958 as American Club of Therapeutic Radiologists ${ }^{1}$, enabled associated member status to radiation physicists in 1966, and full membership in 1978 [2]. The European Society for Radiotherapy and Oncology (ESTRO) was founded in 1980, with immediate associate membership for physicists. "The founders were determined to realise their dreams of integrating research and clinical practice in the new Society" and physicists and biologists were accepted as full members in 1982 [3]. The American Association of Physicists in Medicine (AAPM), founded in 1958, represents scientists ("generally known as medical physicists") whose clinical practice is dedicated to ensuring accuracy, safety and quality in the use of radiation in medical procedures such as medical imaging and radiation therapy [4]. The European Federation of Organisations for Medical Physics (EFOMP) was founded in 1980, and the first policy statement in 1984 [5] stated: "It is one of the objectives of the Federation to formulate recommendations for education and training in Medical Physics that might be suitable for the establishment of comparable European Qualifications". This policy statement described the results of a questionnaire in 19 European countries, concerning the entry qualification, the type and duration of additional education, the nature of final examination, accreditation and official recognition. The results of the 1984 survey showed that, in some countries, several levels of medical physics expertise were already formalised. In this policy statement, the EFOMP Council also stated that the entrance level should at least be a $\mathrm{BSc}^{2}$ in physics [5] and that the medical physicist training should consist of at least $300-400 \mathrm{~h}$ of lectures, seminars and practical sessions combined with on-the-job training (residency) in hospitals, for at least two years. The training could concentrate on one medical physics speciality, but the courses should also include other aspects of medical physics. Senior level could be obtained by further training and obtaining higher academic (MSc, PhD) degrees.

Following the first EFOMP policy statement in 1984, much has happened. The survey on the status of training and education of medical physicists in Europe was repeated in 2005-2006 [6], with responses from 25 countries, and extended with 2 North American countries (USA and Canada) as well as Australia and New Zealand in 2010-2011 [7].

\footnotetext{
1 ACTR, name changed to ASTRO in 1983

${ }^{2}$ BSc refers to EQF level 6 and MSc to EQF level 7 [22].
}

Furthermore, EFOMP has formulated several policy statements (i) on the level and content of Medical Physics Education and Training Schemes [8-12], (ii) on the roles and responsibilities and status of the medical physicist [13-15], and (iii) on recommended guidelines on National Registration Schemes for Medical Physicists $[16,17]$. In addition, the European Commission (EC) published European guidelines on Medical Physics Experts (MPE) [18] where the role of medical physicists in a clinical environment, the qualification framework, recognition arrangements and staffing levels were defined. These EC guidelines known as RP-174, only define the title of Medical Physics Expert (MPE) but include a detailed qualification framework by which medical physicists progress through academic and clinically based training followed by advanced clinical experience and CPD to present themselves for recognition as an MPE.

ESTRO-EFOMP jointly issued guidelines for the education and training of medical physicists in RT in 2004 [19], which were updated in 2011 [20]. The 2011 core curriculum (CC) for medical physicists in RT states: "According to the EFOMP recommendations given in Policy Statement No.12 [11], this revised curriculum assumes that the entrant into specialist training as a Medical Physicist in RT has a degree in physics (typically 180 ECTS $^{3}$ ). Post graduate education in Medical Physics should consist of formal university education at the level of a Master's degree (Master in Medical Physics, up to 300 ECTS), followed by accredited practical training at a hospital (on job training) for at least two years, working under the supervision of an experienced medical physicist". With the term core curriculum we refer to a minimum level of knowledge, skills and competences required to achieve the certification of MPE in RT. The EFOMP policy statement 12.1 [12] and the European Commission Guidelines on MPE [18] give information on the role and education requirements for the MPE in Europe. Fig. 1 of the RP174 document illustrates the pathway "The Qualification Framework for the MPE in Europe". In line with these latest EC guidelines and following the EC Council directive 2013/59/EURATOM [21], a Medical Physics Expert is defined as a Medical Physicist who has reached EQF level 8 in one or more chosen specialties of clinical Medical Physics. MPE is hence used in the remainder of this paper.

One of the key goals of EFOMP has been to contribute to the harmonisation of the education and training of medical physicists in Europe in order to facilitate cross-border mobility of professionals. In practice, however, the entrance levels, duration and content of education and status of formal recognition practices are different in the various European countries. The current ESTRO-EFOMP CC for training of medical physicists in RT [20] will soon be updated in line with recent developments in the field. In this CC, recommendations will be given regarding the education entry level, duration and content of the training of medical physicists, aiming at harmonization of curricula across Europe, and preparing for the increasing demands on knowledge and skills of medical physicists. This updated CC will encompass the challenges of the rapidly increasing technological complexity of radiation treatments and the increasing demands on quality and risk management. For some countries, the recommendations may be ambitious, but should still be realistically achievable with time, and should represent a standard basis on which each country can tailor its own CC with the goal of achieving harmonization of education and training of MPEs across Europe.

\footnotetext{
${ }^{3}$ ECTS $=$ European Credit Transfer and Accumulation System, 1 ECTS = 25-30 study hours, varying among countries; 180 ECTS is typically a BSc in physics.
} 
This study presents the results of a survey of currently used entrance level requirements, contents, durations, methods of training, assessments and recognitions of medical physicists in Europe. The analyses will serve as a basis to provide recommendations on the structure and the organization of the training to achieve the certification of Medical Physics Expert for the update of the 2011 ESTRO-EFOMP CC. This CC focuses on the education and training of MPEs in RT specifically.

\section{Material and methods}

In April 2019, the ESTRO Physics Committee and EFOMP created a working group to update the CC for medical physicists in RO. The first meeting of this group took place in September 2019 at the ESTRO office in Brussels. The group included representatives of 17 European Medical Physics National Societies (NS), representatives of the ESTRO physics committee (chair and members sitting in the education council), Young ESTRO Physics Committee and of the EFOMP Professional Matters, Education \& Training, Science and European Matters Committees. During this first meeting, it was agreed to launch a survey on the education and training requirements for medical physicists in Europe to be used as input for updating the CC.

An online questionnaire (Supplement S1) was created and sent to representatives of the $36 \mathrm{NS}$ in the ESTRO-EFOMP NS register.

The questionnaire comprised 35 questions related to the training of medical physicists. The survey also included questions about the composition of members of the NS (total number, number of members working in RT), NS's role in education, pre-education requirements to be eligible for medical physics educational programs, national educational programs (format, content, duration and financial support), existence of a core curriculum and recognition as a registered healthcare profession. Although most of the questions had predefined optional answers for ease of evaluation free text was allowed to give additional information if needed. The survey was initiated on October 2019 and closed on December 2019.

After the first analysis, a second set of questions (Supplement S2) was sent to the NS to further clarify some answers. These questions focussed on university degrees and, in particular, on the number of ECTS for mathematics and fundamental physics required to have access to the medical physics educational programmes (pre-education level) and on the duration of the medical physics educational programme. The answers for this second round were collected in 4 weeks.

\section{Results}

Of the 36 NS contacted, 26 responded to the survey (response rate of $72 \%)$.

\subsection{National societies and national training schemes}

Of the twenty-six responding NS, eight stated they were scientific societies only, six were professional societies only, ten declared to be both professional and scientific societies, while two did not answer.

The number of affiliated members varied among the different European countries, ranging from 19 to 4600 with a median value of 200 . The percentage of members working in RT varied from $16 \%$ to $86 \%$ with a median of $47 \%$ (23 out of 26 NS responded to this question). The frequency distribution of NS's members working in RT is shown in Fig. 1.

Medical Physics is recognized as a healthcare profession in 19 out of 26 countries $(73 \%)$.

Out of the twenty-six NS, twenty (77\%) reported having a national training scheme (NTS) for the qualification of medical physics expert (EQF level 8 [22]).

Of the six countries without an NTS, two had a local hospital training program, one required the MPE candidate to train abroad under the supervision of a certified MPE, while three required no further training after the master's degree. The requirements for a local hospital training program or to be directly hired by the hospital were a master's degree in Medical Physics (2 countries) or in Physics (2 countries). Two countries without an NTS did not specify the requirements for local training or to be hired by a hospital.

\subsection{Pre-education level and other admission criteria for MPE training}

Pre-education requirements to enter the MPE training scheme varied widely among countries and are summarized in table 1 . Most often, an MSc in Physics, Medical Physics or closely related field was defined as a minimal requirement (13 countries) and a BSc in Physics was specifically required by four countries before the MSc. For the remaining seven countries, a BSc was the minimal requirement to enter the training scheme. In two of these seven countries, the training scheme itself contained an MSc degree, obtained after a BSc degree in physics or engineering.

The number of ECTS in fundamental Physics and Mathematics (explicitly defined as Mechanics, Electromagnetics, Quantum

\section{Percentage of members of the NS working in RT}

\section{2}

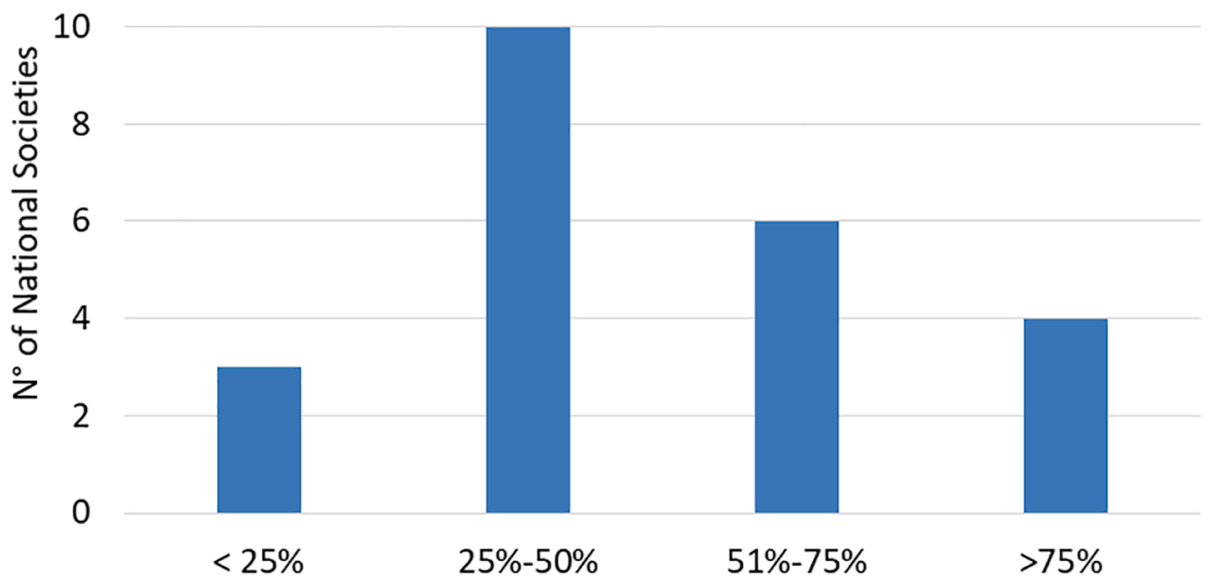

Fig. 1. Frequency distribution of NS's members working in RT. 
Table 1

Pre-education requirements and admission criteria for MPE national training schemes (for 20 NS with an NTS).

\begin{tabular}{ll}
\hline Pre-educational level requirements & $\mathrm{N}^{\circ}$ of NS \\
\hline MSc medical physics & 6 \\
MSc physics & 5 \\
MSc engineering or other science & 2 \\
BSc physics & 5 \\
BSc science & 2 \\
Number of ECTS in fundamental physics and mathematics required & $\mathbf{N}^{\circ}$ of NS \\
$50-100$ & 5 \\
$101-200$ & 3 \\
$>200$ (max $=300)$ & 9 \\
No answer & 3 \\
Admission criteria & $\mathbf{N}^{\circ}$ of NS \\
Only university results & 3 \\
Interview & 1 \\
University results and interview & 5 \\
Entrance exam & 4 \\
Be employed in a hospital & 2 \\
No specific requirements & 3 \\
No answer & 2 \\
\hline
\end{tabular}

*science $=$ related science, such as biomedical or engineering

Mechanics, Nuclear Physics, Thermodynamics, Optics, Algebra and Calculus) required to enter the training scheme varied amongst countries regardless of the required university degree. It appeared that four of the countries requiring more than 200 ECTS of Physics did not require a MSc degree as entrance level for their MPE training scheme (i.e. the BSc degree itself should be longer than three years and contain almost exclusively fundamental Physics and Mathematics).

Twelve NS reported that the number of candidates entering the MPE training program was fixed (almost in all cases by the government) and eleven reported no restrictions.

Besides required pre-education, other admission criteria for the training programs varied also (Table 1).

In total, eight out of twenty-two NS responding to this question (20 with a NTS), reported that the minimum requirements to enter the training scheme would likely change in their country in the near future. In particular, two of them said that the minimum requirement will change from BSc to MSc while one NS reported a plan to establish an NTS in the near future.

\subsection{MPE training program}

In most countries, the training period is dedicated to the three disciplines of medical physics (RT, nuclear medicine and radiology). Total training duration either for NTS or local hospital training, varied from one to five years with a median value of three years. Seventeen countries out of twenty-two (77\%), declared that medical physics trainees are paid. In ten countries they are paid by the hospital (59\%), in six by the government (35\%), while in one country some of the trainees are paid by the government (those who scored best at the admission exam of the specialization school), and some by the hospital.

There was a variation in the percentage of training dedicated to radiotherapy physics with respect to the other disciplines of medical physics, ranging from $25 \%$ to $100 \%$ with a median value of $50 \%$.

A variation in the proportion of time spent on lectures at the university or training in the hospital has been reported by the different countries, as shown in Fig. 2. The median value of the ratio of time spent on university lectures and hospital training was $25 \% / 75 \%$ respectively, with seven countries providing training completely in the hospital.

A research project as part of the training was included in fifteen of twenty-three countries (65\%), (three NS of countries with no NTS did not answer). Of these, only ten assigned ECTS points for the research project (see Table 2), with the output being either a thesis or the publication of a scientific article in a peer reviewed journal, or an abstract at an international congress.

MPE candidates were required to defend a final thesis to obtain the training certificate in $36 \%$ of the countries. Of these, two countries stated that a research thesis was required to obtain the Master's degree in Medical Physics.

Eleven out of twenty (55\%) NS with an NTS declared that hospitals training MPEs needed to be certified by national authorities or professional/scientific societies.

Several methods for assessing Medical Physicists in training were reported by the different countries as shown in Table 2. In particular, the external bodies responsible for the continuous evaluation were the Ministry of Health ( 4 countries), National Societies ( 2 countries), bodies

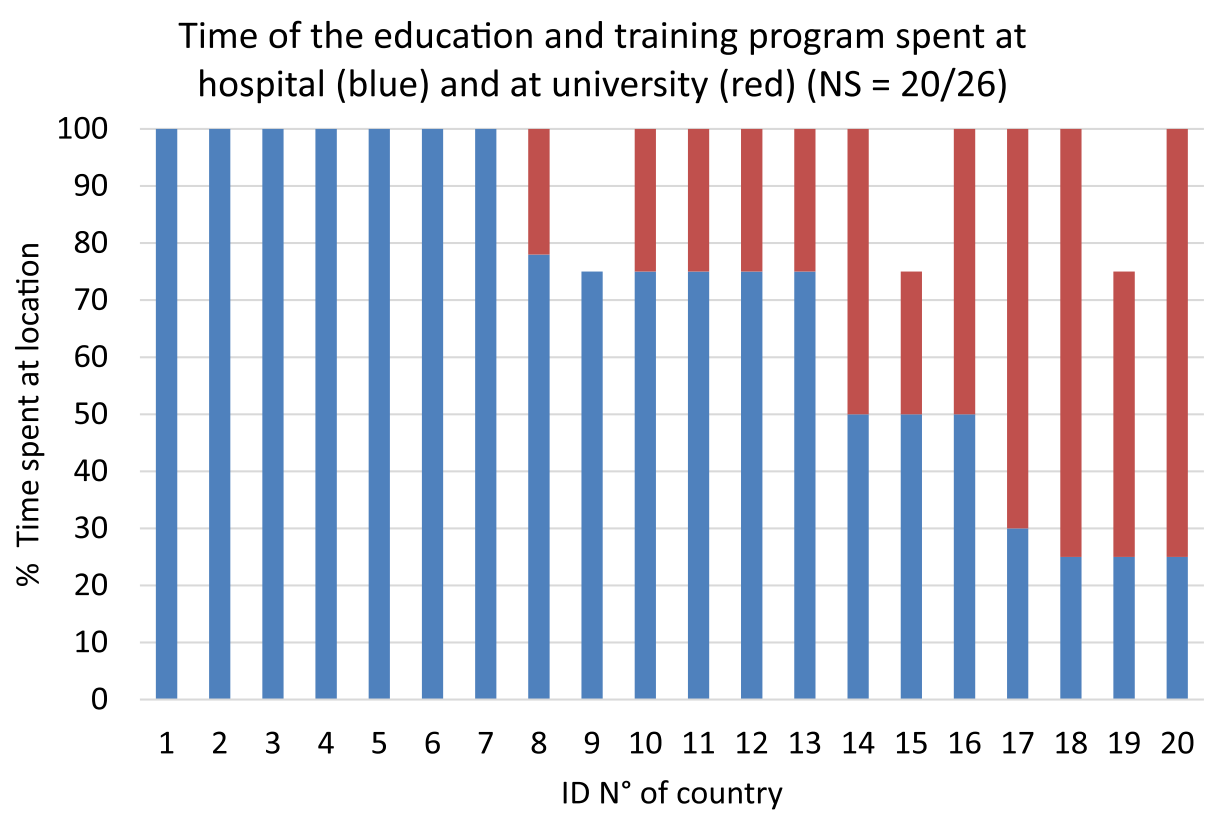

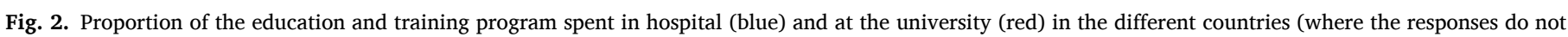

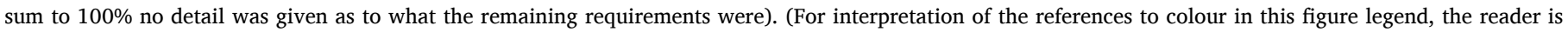
referred to the web version of this article.) 
Table 2

Structure of education and training of MPEs.

\begin{tabular}{|c|c|c|}
\hline Training & Range & Median \\
\hline Length of training & $1-5$ yrs & 3 yrs \\
\hline Percentage of time dedicated to RT & $25 \%-100 \%$ & $50 \%$ \\
\hline \multicolumn{3}{|c|}{ Division of training delivered between University and Hospital (median) } \\
\hline University & $25 \%$ & \\
\hline Hospital & $75 \%$ & \\
\hline \multicolumn{3}{|l|}{ Research project $(\mathrm{N}=23)$} \\
\hline yes & 15 & \\
\hline no & 8 & \\
\hline \multicolumn{3}{|l|}{ Ranges of ECTs for the research project $(N=10)$} \\
\hline $5-20$ & 4 & \\
\hline $21-40$ & 3 & \\
\hline $41-60$ & 3 & \\
\hline \multicolumn{3}{|c|}{$\begin{array}{l}\text { Final outcome of the research project required to obtain the MPE certificate (N } \\
=23 \text { ) }\end{array}$} \\
\hline yes & 9 & \\
\hline no & 14 & \\
\hline \multicolumn{3}{|l|}{ Evaluation methods $(\mathrm{N}=23)$} \\
\hline Continuous evaluation by an external body & 8 & \\
\hline Continuous evaluation by the training hospital & 21 & \\
\hline Exam at the end of the NTS & 6 & \\
\hline National exam at the end of the NTS & 7 & \\
\hline
\end{tabular}

in federal states (1 country) and National School of Healthcare Science (1 country).

\subsection{MPE certification}

Only six out of the twenty-six NS (23\%) declared that a trainee automatically becomes an MPE after successfully finishing the training program. In four countries (15\%) the MPE title is still not used, so only specialist/qualified medical physicist is acknowledged. In five countries (19\%) the medical physicist training does not provide the MPE title directly after finishing the training program but requires further advanced training and experience building for an additional two to five years, to reach the certification. During this period, the medical physicists may work in the clinical environment without supervision as qualified medical physicists, but they must show full-time advanced clinical experience and provide evidence of continuing professional development to be eligible for the MPE certification. The remaining eleven NS (42\%) did not provide an answer.

The characteristics of the structure of education and training in MPE are summarised in Table 2.

\subsection{National core curriculum}

Twenty out of the twenty-six (77\%) NS confirmed the existence and use of a national CC for the education of medical physicists in RT in their country. Four NS indicated not having a CC available, (3 of them from countries with no NTS), while two stated that several curricula (depending on the educational programmes of Universities) are being used in their country (one has a NTS but from that, several curricula are developed).

The majority of the national CC are based on competences (16), of which two use the CanMEDS framework. Seven out of the twenty NS with an NTS (35\%) have implemented or upgraded their CC in 2018 or 2019. Two NS reported annual modification of the programmes. Eleven out of the twenty NS (55\%) with long-standing, unchanged programmes, declared the need to revise their CCs soon.

Half (10) of NS used the latest version (2011) of ESTRO-EFOMP CC as a basis in developing their own national curriculum. The reasons for not using the latest version of ESTRO-EFOMP CC by the remaining NSs (10) were reported as follows:

- A CC was already in place when the ESTRO-EFOMP CC was published (3);
- different structure of medical physics training in the countries, i.e., ESTRO-EFOMP CC focused on radiotherapy only, while the national CCs covers also imaging, nuclear medicine and hospital physics (2); - the national CCs were created on the basis of other recommendations/regulations (i.e., RP174, IAEA, EFOMP, CAMPEP) (3).

- Two NS did not indicate any specific reasons for not using the latest version of ESTRO-EFOMP CC during the development of their own CC.

\section{Discussion}

In table 3 , some results of the 2020 survey on the current practice of entrance level requirements, content, duration, and method of training are compared with results from previous surveys $[5,6]$.

Table 3 shows important progress over the years. In particular, it highlights that from 1984 until 2020 the number of countries with an NTS more than doubled (from 9 to 20), but still six (23\%) of the responding NS reported no NTS. Those countries, except one, had a low number of facilities, so MPEs are trained only in one or few large institutions or abroad. Medical Physics is now recognized as a healthcare profession in more countries compared to the past (increase from 6 to 19 countries). However, a full recognition is not always achieved during the training (23\% of the NS declared that the MPs in training are not paid yet and the training is not always acknowledged by the Ministry of Health).

Although the median of the training period has remained constant over the years ( 3 years), more emphasis is currently given to the hospital training rather than the University education. Indeed, the most common ratio of theoretical lectures and practical work at the hospital was $25 \%$ $175 \%$, respectively. In the present survey a research project as part of the training was required in most of the countries (65\%), with the output being either a thesis ( $36 \%$ of the countries), or the publication of a scientific article in a peer reviewed journal, or an abstract at an international congress. A thorough training in scientific principles and research methods is essential for the MPE, with service development oriented research and innovation being part of their core responsibilities.

Over the years, the most common pre-education required to enter the training program or to be directly hired by the hospital is a Master's degree in physics or medical physics.

The EFOMP policy statement 12.1 [12] and the European Commission Guidelines on Medical Physics Expert-RP 174 [18] give very clear and detailed information on the educational qualifications and training requirements for the Medical Physics Expert in Europe (see Fig. 1 of RP174). First, a BSc in physics or equivalent is required. After that, an MSc in medical physics or equivalent is required. Then $2+2$ years of

Table 3

Education and training structure for MPE as assessed by the current and previous surveys.

\begin{tabular}{llll}
\hline Number of countries with: & $\begin{array}{l}\text { EFOMP PS 1 } \\
1984[4]\end{array}$ & $\begin{array}{l}\text { EFOMP 2005 } \\
{[19]}\end{array}$ & $\begin{array}{l}\text { Current Survey } \\
2020\end{array}$ \\
\hline Response to survey & 19 & 25 & 26 \\
National Training Scheme & 9 & 16 & 20 \\
University training scheme & 0 & 4 & 2 \\
$\quad$ only & 10 & 4 & 3 \\
On-the-job training only & 0 & 1 & 1 \\
Training abroad & $1-4$ years & $2.5-9$ years & $1-5$ years \\
Duration of the training & (median 3 y) & (median3 y) & (median3 y) \\
& 6 & 14 & 19 \\
National registration of & & & \\
MPE as health & & & \\
professional & 1 & 7 & 15 \\
Pre-education to enter the training or to be directly hired by the hospital: \\
BSc physics & 8 & 9 & 2 \\
MSc (medical) physics & 0 & 0 & 2 \\
BSc in science* & 0 & 0 & 2 \\
MSc in science* & 10 & 9 & \\
No information & &
\end{tabular}


structured accredited clinical training and advanced clinical experience are required to be certified as an MPE by the competent authorities.

For comparison, we also state the current requirements in Australia, New Zealand, the USA and Canada. The current entry levels for the Medical Physicist training in Australia and New Zealand are a BSc with major in physics and an MSc in medical physics (Australasian College of Physical Scientists and Engineers in Medicine (ACPSEM), [23]). The medical physics training in RT is a 3-year education program. Further a publication in a peer reviewed journal is a requirement. In the USA and Canada, according to the graduate standards, the students entering a medical physics graduate educational program must have a BSs or MSc in physics or related science with "sufficient physics", a $\mathrm{PhD}$ in physics or "closely related field". The completion of the MP program typically takes two academic years (Commission on Accreditation of Medical Physics Education Programs (CAMPEP), [24]).

The results of the survey show that six years after the publication of the RP174 guidelines for the training of MPE [18], these have not yet been (fully) implemented in most European countries. To reach consensus on the training length to be licensed as MPE is of utmost importance, as in the Council Directive 2013/59/EUROATOM [22] only the title of MPE is mentioned, with no further references to MP or MP specialist. Article 14 of this directive gives the member States the responsibility for ensuring that arrangements are made for the establishment of education, training and retraining to become medical physics experts, in relation to the type of practice. The Directive 2005/36/EC [25] established the mechanism for automatic mutual recognition of qualifications for medical doctors according to training requirements within all Member States, based on the length of training in the specialty and the title of the qualification. Therefore, to facilitate cross-border mobility as medical specialties, there is an urgent need to define the minimum number of years, format and content of postgraduate training to become an MPE, therefore harmonizing the training of medical physicists/MPE throughout Europe. To obtain this, the entrance level for training could be defined as a BSc in physics or strongly related science, with a high content of fundamental mathematics and physics (determined by a minimum number of ECTS in these topics), followed by a (medical) physics MSc degree. After that, a postgraduate training in medical physics which includes substantial clinical residency training, would then result in clinical certification pending successful performance at assessment. The training period should be sufficient to obtain the competences to become an independent specialist. In particular, the CanMEDS roles framework [26] formalizes additional clinical skills and perspectives thus bringing the MPE professionals closer to their medical colleagues and more clearly defining the medical physics profession as a healthcare profession.

With the increasing technological complexity of radiation oncology and medical physics in general, and greater demands on quality and risk management, it seems that the current median of three years of training is on the low side. The enhanced technological complexity also comes with an increasing need for MPEs to have high-level training in research and innovation, which also takes time. The current average of three years is also shorter than generally required for training in medical specialties. As MPEs in radiation oncology have a crucial clinical role, as the other professionals, a large percentage (a median value from the survey of $75 \%$ ) of the program should be spent in a hospital to acquire competences and skills that are most relevant to clinical work. The high level of qualifications required to enter the training combined with the intensive level of training demands that the residency (academic education and hospital training) should be paid. Certification (or licensing) as an MPE after the training should be based on objective assessment of completion of a training program that fulfils the national guidelines. Hospitals, universities, or healthcare facilities that provide MPE training should be certified by an official authority responsible for training programs. The training facility and the quality of the MPE training should be regularly audited by the official authority.

\section{Conclusions}

Although previous joint efforts by EFOMP and ESTRO have resulted in significant progress in establishment and harmonization of formal radiotherapy MPE training programs in Europe, the entrance level, duration and contents of the current training programs still show significant variations. While acknowledging differences between countries, the updated CC should aim at securing an optimal yet realistic level of training requirements for safe and effective practice, which will contribute to further harmonization of MPE training, in line with EU guidelines. This survey contributes valuable information to assist with the design and development of the CC that not only provides the pathway to basic training but reaches further to describe professional development to expert level.

\section{Acknowledgements}

The authors gratefully acknowledge Viviane Van Egten, Alessandra Nappa and Simone De Ioanna of the ESTRO office for their support for survey preparation and data collection.

\section{References}

[1] Roles and responsibilities, and education and training requirements for clinically qualified medical physicists, International Atomic Energy Agency, Vienna, Austria (2013) https://www-pub.iaea.org/MTCD/Publications/PDF/Pub1610_web.pdf.

[2] https://www.astro.org/About-ASTRO/History/A-Historical-Timeline.

[3] Three decades of ESTRO; a vision for cancer cure. https://estro.org/ESTRO/me dia/ESTRO/About/estro-book-final-version-copy.pdf.

[4] www.aapm.org.

[5] EFOMP Policy Statement 1: Medical Physics Education and Training: The present European Level and Recommendations for its Future Development, 1984. https: //www.efomp.org/uploads/policy statement nr 1.pdf.

[6] Eudaldo T, Olsen K. The present status of medical physics education and training in Europe: an EFOMP survey. Phys Med 2008;24(1):3-20. https://doi.org/10.1016/j. ejmp.2007.09.022.

[7] Stefanoyiannis AP, Christofides S, Psichis K, Geoghegan DS, Gerogiannis I, Round $\mathrm{WH}$, et al. The education and training of clinical medical physicists in 25 European, 2 North American and 2 Australasian countries: similarities and differences. Phys Med 2012;28(3):183-90. https://doi.org/10.1016/j. ejmp.2011.07.001.

[8] EFOMP Policy Statement 3: Radiation Protection of the Patient in Europe: The training of the Medical Physicist as a Qualified Expert in Radiophysics,1988. https: //www.efomp.org/uploads/policy statement nr 3.pdf.

[9] EFOMP Policy Statement 8: Continuing Professional Development for the Medical Physicist. Phys Med 1998; XIV (2): 81-83, https://www.efomp.org/uploads/policy statement_nr_8.pdf.

[10] EFOMP Policy Statement 9: Radiation Protection of the Patient in Europe: The Training of the Medical Physics Expert in Radiation Physics or Radiation Technology. Phys Med 1999; XV (3): 149-153, https://www.efomp.org/uplo ads/policy_statement_nr_9.pdf.

[11] EFOMP Policy Statement 12: The present status of Medical Physics Education and Training in Europe. New perspectives and EFOMP recommendations. Phys Med 2010; (26) 1-5. doi: 10.1016/j.ejmp.2009.02.005.

[12] EFOMP Policy statement 12.1: Recommendations on Medical Physics Education and Training in Europe 2014; Caruana CJ, Christofides S, Hartmann GH. Phys Med. 2014 Sep;30(6):598-603 , doi: 10.1016/j.ejmp.2014.06.001.

[13] EFOMP Policy Statement Nr. 2: The Roles, Responsibilities and Status of the Clinical Medical Physicist, 1984., https://www.efomp.org/uploads/policy_statem ent_nr_2.pdf.

[14] EFOMP Policy Statement Nr. 7.1: The Roles, Responsibilities and Status of the Medical Physicist Including the Criteria for the Staffing Levels in a Medical Physics, S. Evens, S. Christofides, M. Brambilla; Phys. Med. 533-540, 2016., doi: 10.1016/j. ejmp.2016.03.001.

[15] EFOMP Policy Statement Nr. 16: The role and competences of medical physicists and medical physics experts under 2013/59/EURATOM; C.j. Caruana, V. Tsapaki, J. Damilakis, M. Brambilla, G.M. Martin, A. Dimov, H. Bosman, G. Egan, K. Bacher, B. McClean, Phys. Med. 48; 162-168, 2018., doi: 10.1016/j.ejmp.2018.03.001.

[16] EFOMP Policy Statement 6: Recommended guidelines of National Registration Schemes for Medical Physicists. Phys Med 1995; XI (4): 157-159, https://www. efomp.org/uploads/policy_statement_nr_6.pdf.

[17] Christofided S, Isodoro J, Pesznyak C, Bumbure L, Cremers F, Schmidt WFO. 6.1: recommended guidelines on national registration schemes for medical physicists. Phys Med 2016;32:1-6. https://doi.org/10.1016/j.ejmp.2016.01.479.

[18] Guidelines on medical physics expert. European Commission. Radiat Prot 174, 2014. https://ec.europa.eu/energy/sites/ener/files/documents/174.pdf.

[19] Guidelines for education and training of medical physicists in radiotherapy. Recommendations from an ESTRO/EFOMP working group. Eudaldo T, Huizenga 
H, Lamm IL, McKenzie A, Milano F, Schlegel W, Thwaites D.I, Heeren G. Radiother Oncol 2004;70:125-135. doi: 10.1016/j.radonc.2004.02.004.

[20] The updated ESTRO core curricula 2011 for clinicians, medical physicists and RTTs in radiotherapy/radiation oncology. Eriksen JG, Beavis AW, Coffey MA, Leer JWH, Magrini SM, Benstead K et al. Radiotherapy and Oncology, vol. 103, iss. 1, (2012), pp. 103-108. doi:10.1016/j.radonc.2012.02.007.

[21] EU Council Directive 2013/59/Euratom of 5th December https://eur-lex.europa. eu/LexUriServ/LexUriServ.do?uri=OJ:L:2014:013:0001:0073:EN:PDF.

[22] Recommendation of the European parliament and of the Council of 23 April 2008 on the establishment of the European Qualifications Framework for lifelong learning. Official Journal of the European Union, C 111/1, 6. 5. 2008.

https://eur-lex.europa.eu/legal-content/EN/TXT/PDF/?uri=CELEX:32008H0506 (01)\&from $=\mathrm{EN}$.

[23] https://www.acpsem.org.au/Our-Work/TEAP-Certification-/ROMP http://www. campep.org/gp.asp.

[24] Peeters M. Free movement of medical doctors: the new Directive 2005/36/EC on the recognition of professional qualifications. Eur J Health Law 2005;12(4): 373-96. https://doi.org/10.1163/157180905775088586.

[25] www.royalcollege.ca/rcsite/canmeds/canmeds-framework-e. 